http://dx.doi.org/10.4314/gjl.v7i2.10

\title{
SHIFTING SANDS: LANGUAGE POLICIES IN EDUCATION IN GHANA AND IMPLEMENTATION CHALLENGES
}

\author{
Akosua Anyidoho
}

\begin{abstract}
This paper discusses the lack of consistency in language in education policies which have been endorsed by various governments of Ghana. A small-scale investigation carried out in two regions of Ghana exposes the current abysmal level of attention given to the indigenous languages in the schools in the cosmopolitan areas especially. It argues that the neglect of the indigenous languages might result in a communication gap between the non-English speakers and the educated, English-speaking elite who tend to represent the former group in government. This situation in turn could impede economic development and the democratic process as the voices of the marginalized nonEnglish speakers would not be fully represented in governance. Similarly, the language shifts that the education system tends to promote, in the long term could result in the endangerment or near extinction of the local languages and the indigenous knowledge embodied in them. The paper ends with recommendations towards addressing the challenges associated with the implementation of the 2004 language policy in education.
\end{abstract}

Keywords: Communication, L1 in education, L1 literacy, indigenous language in education, language of instruction, NALAP (National Literacy Acceleration Programme), language policy implementation

\section{Introduction}

At the onset, I would like to observe that communication is an indispensable tool in human society as it is an avenue for humans to successfully give or share with others their thoughts, feelings, ideas, and information. Though humans communicate through body movements, signs, and other means, by far superior in terms of accuracy, effectiveness and efficiency is speech and the writing systems based on it. When people come together to achieve a common purpose in the home, community, society, and nation, speech becomes a requisite tool for the success of that enterprise. Basic phenomena such as the socialization of the young and the transmission of culture are 
very much enhanced through verbal language. In the globalised world, classroom education, which is the most viable avenue for training and passing on information and knowledge to younger generations, is also severely hampered without speech and writing.

Successful communication becomes possible when the interlocutors share a common language. Therefore, issues related to satisfactory communication of information to all the citizens in multilingual societies have aroused debates, especially as to the role the various languages should play in the life of the people. Arguably, the most passionate debates concern the place of indigenous languages in societies where world-wide languages such as English have become official languages. These debates are the result of the understanding that language is one of the most far-reaching element of identity. It is a tool of knowledge creation and dissemination as well as the repository of the accumulated knowledge and of the culture of a society.

Though generally individuals learn their home language through exposure in their environment, in contemporary times, the school is viewed as the main avenue for enhancing competencies in the spoken language and for the acquisition of reading and writing skills needed for continuous learning and personal development. As such, countries the world over develop language in education policies through which the language skills of their citizens are sharpened. In multilingual countries, such policies would indicate which language(s) should be used as the medium of instruction and at what stage as well as other languages that would be taught at the various levels of education. How has Ghana fared in using the school system for this purpose? This question is discussed next.

\section{Language Policy in education in Ghana}

Since western-style education was introduced in multilingual Ghana, language-ineducation policy has had a chequered history as different government administrations on assumption of office invariably decide to modify or make a complete shift in whatever policy existed before they came into office. For a detailed historical account and analysis of this situation, see McWilliam and Kwamena-Poh (1975), NkansaKyeremateng (1996), Markin-Yankah (1999), Anyidoho (2004), Owu-Ewie (2006), Anyidoho and Dakubu (2008), Anyidoho and Anyidoho (2009) and Ansah (2014). Rather than reiterating information that is covered by these and other writers, this paper describes the policies that have come into existence since 2000, bringing to the fore the lack of consistency in language-in-education policy in Ghana. 
In January 2001, the Director General of the Ghana Education Service ${ }^{1}$ (GES) signed a letter that sought to remind its officials, teacher associations and all heads of Basic Schools ${ }^{2}$ in the country about the then existing language policy originally announced in 1971. Part of this widely distributed letter is as follows:

Essentially, the Policy is that, "instruction at the Lower Primary Level (Primary 1-3) will be conducted in the pupil's mother tongue, or in the major Ghanaian Language of the local area, while English will be studied as one of the subjects offered at the Lower Primary Level. From Primary 4 onwards, class instruction will be conducted in English; and the Ghanaian Language will then be studied as one of the subjects offered.

The Director General rationalized the policy as follows:

The fundamental philosophy underlying the Ghanaian Language Policy in our schools is to enable the individual acquire a sense of cultural identity and make him/her literate in his/her own mother tongue. Another essential factor is that basic literacy in one's mother tongue or the local language enhances the child's ability to transfer and apply acquired learning skills in the local language to proficiency in learning English and other languages. (Signed by the Director General of GES, Jan. 2001)

The measures that were being taken at the time to facilitate effective implementation of the policy were outlined in the letter, i.e. printing of textbooks, training and posting of teachers.

However, within 17 months of the circulation of this reminder, a policy change was declared by the Minster of Education, which compelled the GES Director General to send another circular to inform the same recipients that:

\footnotetext{
${ }^{1}$ The Ghana Education Service is the implementing body of education policies formulated by the Ministry of Education, a government department.

2 The Basic School level consists of a two-year kindergarten (KG 1 \& 2), three-year Lower Primary (P1 - P3), three-year Upper Primary (P4 - P6) and three-year Junior High School (JHS 1 - JHS 3).

Graduates of the Basic School proceed to a three-year Senior High School (SHS 1 - SHS 3)
} 
At its meeting in May 2002, Cabinet deliberated on revision of the Ghanaian Language policy and approved the New (Revised) Language Policy for implementation by the GES as follows:

a) English should replace vernacular as the medium of instruction in the first three years of Primary schooling.

b) Every Ghanaian child must study one Local Language from Primary One up to the Senior Secondary School Level.

c) Students should be encouraged to study the French Language

Regional and District Directors of Education, General Managers of Education and Proprietors/Proprietresses of Private Schools are advised to take note of the revised Policy and implement it accordingly. (Signed by Director General of GES, August 2002.)

It is important to note that prior to the May 2002 announcement, the government had set up an Education Review Committee to study the educational system and its related issues and to make recommendations for improvement. For readers to comprehend the motivation for the setting up of the committee, we recall that in 1987, the People's National Democratic Congress (PNDC) ${ }^{3}$ government, which had been in office since 1981, under pressure from the World Bank and the International Monetary Fund, commenced a major educational reform which reduced basic and secondary education from $15 y$ rs to $12 y r s$ and increased university education from $3 y r s$ to $4 y r s$. Two objectives of the reform were, (a) compulsory and universal nine-year basic education (P1-JHS3), and (b) equipping young people with employable skills. Therefore, instead of focusing mainly on academic content, the reform introduced technical and vocational skills training in the Basic School curriculum. Though the reform might have been well intended, it was perceived that the government had rushed to implement it without prior adequate preparation, including the training of teachers, provision of school infrastructure, supply of books and equipment and education of the general public. Consequently, when the majority of the first batch of graduates from the new school

\footnotetext{
${ }^{3}$ The People's National Democratic Congress (PNDC) government, which came into power in 1981 through a military coup d'état, was headed by Flight Lieutenant Jerry John Rawlings. While still in office, in 1992, this leader of the military junta, stood and won the general elections on the ticket of a political party which he founded, the National Democratic Congress (NDC). Rawlings then metamorphosed into a democratically elected president and had two four-year terms in office, 1992 2000. His party lost the elections to the New Patriotic Party (NPP).
} 
system failed their final examinations, criticism of the reform was intensified, and suggestions were made for a return to the former system.

For our present purpose, it is important to mention that in addition to retaining the local language as the medium of instruction in P1 - 3, the 1987 reform made the study of the local language compulsory and examinable throughout Basic and Senior High School levels. This requirement was another area of dissatisfaction and criticism, stemming from the negative attitude that Ghanaians generally have about the indigenous languages. The contention was that the school curriculum was crowded with many non-essential subjects such as the indigenous languages and that students faced enormous challenges in learning all of them efficiently.

The defeat of the NDC in the 2000 general elections gave the new administration the opportunity to overhaul what was generally perceived as an illconceived and inefficient educational system. Focusing on language policy in particular, the compulsory study of and examination in the indigenous language became a casualty of the review. The committee recommended that its study should remain mandatory at the Basic School but optional at the Senior High School level. A government white paper published after the submission of the Education Review Committee's report accepted this recommendation. On the issue of the medium of instruction in $\mathrm{P} 1-3$, a section of the white paper reads:

Government accepts the recommendation that the children's home language and Ghana's official language, English, should be used as the medium of instruction at the kindergarten and primary level (2004, p.27).

In the same section, there was a caveat, which seemed to give some weight to the local language as follows:

...where teachers and learning materials are available and linguistic composition of classes is fairly uniform, the children's first language must be used as the dominant medium of instruction in kindergarten and lower primary (p.27 \&28).

The above quotations indicate that the May 2002 policy was later modified to allow the use of both the local language and English as languages of instruction at the lower primary level. This modified policy, for all intent and purposes, was in place from 2008-2016, during the John Atta Mills's and John Dramani Mahama's administrations as no announcement of a change occurred. In fact, in 2016 the Ministry of Education 
received funding from the USAID in support and enhancement of the implementation of the existing policy.

What the preceding discussion reveals is that within a period of three and a half years, January 2001 to August 2004, heads of Basic Schools must have received three circulars stating different language policies they were expected to implement in P1 - 3, i.e. (a) the sole use of local language in teaching, (b) the sole use of English, (c) the use of both local language and English. For ease of reference, these will be henceforth called 2001, 2002, and 2004 policies respectively. The presentation above gives only a glimpse of the general lack of continuity and consistency, a major problem that has dogged language-in-education policy since the inception of formal education in Ghana. A brief overview of policies formulated prior to the 2000 would enable readers to appreciate this chaotic situation.

To begin with, Kwemena-Poh informs us that the Wesleyan Mission that concentrated their educational and evangelistic activities in the south-central part of the country started opening schools in 1838 and emphasized English in the curriculum. A few years later, the Basel (1843) and the Bremen (1847) missions also set up schools in the south-eastern part (Akuapim, Ga and Ewe areas), and used the indigenous languages as media of instruction at the primary level (P1 - P6). Then when the various European trading companies set up schools to train the local people, the classes were conducted in the relevant European language. Even though these decisions on language of instruction were not guided by formal government policies, they set the stage for later events. In 1874 when the British declared the southern part of Ghana a British colony and began establishing public schools, they forced the Christian missions that used mainly the local language in teaching to include English in their curriculum in order to receive funding from the colonial administration. (See Boadi 1976.) The colonial policy of instruction through English was upheld until 1922, when the PhelpsStoke Commission was set up to make recommendations towards the improvement of education in British West Africa. One of the recommendations of the commission was the use of the indigenous language as medium of instruction in the lower primary classes (P1 - P3) and English at the upper levels. In 1951, another committee endorsed the use of the local language medium at the lower primary classes. We note that like previous policies, the local language was to be taught as a subject from P4 onwards, at which point English became the language of instruction.

An important milestone in the history of language-in-education policy in Ghana occurred in 1957 when the government declared English as the medium of instruction at all levels including the very early stages, P1- P3. The choice of English in 1957 seems puzzling since it coincided with the year of Ghana's independence from British colonial domination when the indigenous language option would have been expected. 
Ten years later, the military government of the National Liberation Council (NLC), which ousted the Convention People's Party administration led by Dr. Kwame Nkrumah in 1966, opted for a return to the local language policy. However, the policy allowed urban and private schools to provide instruction in English at the lower primary. The Progress Party civilian administration which was in power from 1969 1971 retained the local language medium in the lower primary.

Then came the military government of the National Redemption Council (NRC) which wrenched political power from the Progress Party government in 1972. This administration modified the existing policy by making the indigenous language the medium of instruction in P1 only. From 1982-2000, the military government of the Provisional National Defence Council (PNDC, 1982-1992), which later became the National Democratic Congress (NDC, 1993-2000), retained the policy it inherited. It would be recalled that in 1987 when the PNDC decided on a restructuring of the education system, it made the study of the local language compulsory and examinable at the Basic and SHS levels, but this policy was short-lived. In 1994 the local language was made an optional subject of study at the SHS level.

In sum, since the inception of formal education and especially since Ghana's independence in 1957, governments have been consistent in the view that the indigenous language should be studied as a subject from the lowest level. What they have differed on are: a) the language of instruction at the Lower Primary level and, b) the stage at which the switch to the English medium should occur if the L1 medium is selected, and c) the level of commitment to the policy option adopted. As the preceding discussion shows, on the first issue, some administrations opted for the L1 medium of instruction and others, the L2. Regarding the second question, P6, P4, and P2 were mandated by different governments. The third issue will be discussed later. Such have been the pendulum swings in language-in-education policy, with most government administrations making some input, but not necessarily from the vantage point of full knowledge and 'insight into the nature of language political processes, such as language attrition, maintenance, spread and development, language policy construction and language policy implementation, and the nature of the relationship between language and society at the macro-level' (Webb 2002: 1). In the light of such frequent changes, an issue that would be of interest to readers is how language-in-education policies are implemented in Ghana and what happens on the ground? This question is the focus of the next section. 


\section{Research on implementation of language policies in Ghana}

Markin-Yankah (1999) assessed the extent of implementation of the 1971 policy in the Shama-Ahanta East District of the Western Region of Ghana. Her subjects were 76 Lower Primary and 76 Upper Primary teachers. She found that though 57\% of P1 - P3 teachers involved in the study reported native competence in the dominant local language, Fante, and 34\% also reported average and above average proficiency in Fante, only 32.9\% taught their lessons in Fante. Giving reasons for their action, some of the teachers erroneously claimed that they were following the Ministry of Education's English-medium policy, and others observed that the children were already proficient in Fante therefore there was no need to 'waste precious time to study or use it in teaching' (p.84). When the P4 - P6 teachers were asked if they taught Fante as a subject, $64.6 \%$ asserted that they did, but $31.6 \%$ answered in the negative while $3.8 \%$ of them failed to respond to this question. Again, when all the 152 Primary $1-6$ teachers were asked whether or not the L1 medium policy for P1 - P3 should be maintained, $81 \%$ of the Lower Primary and 68\% of the Upper Primary teachers observed that it should be changed to English, the official language of the country and which, in their view, was also the language of all school examinations as well as of upward social and economic mobility.

In an attempt to find out the implementation level of the 2004 policy, in March 2011, this writer did a small-scale study in two of the ten administrative regions of the country: East Akim area of the Eastern Region and Dome-Kwabenya area of the Greater Accra Region. The former district lies within the southern forest belt, where many of the residents cultivate cocoa as a cash crop and practice subsistence farming as well. The indigenous language of the area is Akyem Twi, a dialect of Akan, the most widely spoken indigenous language in the country. Because of the cocoa industry, the area has a sizable migrant-settler population from other ethnic groups and also attracts a good number of itinerant labourers during the cocoa planting and harvesting seasons. Apart from the then district capital, New Tafo, which can be categorized as semi-urban, the district is rural, dotted by small towns and villages in relative close proximity. Generally, schools in this research area are typical of those found in rural Ghana, characterized by poor infrastructure.

The Greater Accra Region is found on the south-eastern coast of Ghana and covers Accra, the capital of the country and Tema, a harbour city, and their surrounding areas. Apart from encompassing the largest city in the country, the Greater Accra Region is also the nexus of all government ministries, institutions and agencies as well as of most international companies and organizations. The Greater Accra Region, especially the Accra and Tema metropolis, forms the financial, commercial, 
educational, medical, and social hub of the country and is therefore inhabited by people from all parts of the country and elsewhere. Though the indigenes of the region speak $\mathrm{Ga}$, due to its cosmopolitan nature, the population is ethnically and linguistically diverse. The original settlements of the Ga people are surrounded by many settlements and suburbs, some of which have high concentrations of specific ethnic and linguistic groups. Infrastructure in the schools in this region is slightly better than in those found in the Eastern Region where the research was undertaken.

At the time of the investigation, schools in Ghana were supposed to be participating in the National Literacy Acceleration Program (NALAP), a project designed and coordinated by the GES in its attempt to implement the 2004 language policy. Some background information about NALAP is necessary here.

Having identified low literacy skills as the core problem and the main factor undermining education quality, the GES set up a National Literacy Task Force (NLTF) in 2006 to review the situation and make recommendations for improving the literacy skills of school children. The task force recommended the adoption of the National Literacy Acceleration Program (NALAP),

an instructional approach which provides teachers and pupils of the Lower Primary level (KG 1 - P3) with quality literacy materials, effective instruction and public support to read and write in their local language and in English. The methodology seeks to make pupils literate in their local language for a smooth transition to English. Therefore, by $\mathrm{P} 3$, it is expected that the pupils would be fully bilingual. (GES REPORT, 2010, P.1)

The specific objectives of NALAP are the following:

To equip the majority of children leaving the basic education system with skills of literacy that would improve their learning abilities and serve as a springboard for further academic pursuit. This means that by P3, pupils would be functionally literate and would achieve reading fluency in their local language (L1) and in English (L2). (GES report, 2010:1)

In NALAP, $80 \%$ of instructional time is allocated to the local language in KG and P1 but gradually reduces to $50 \%$ by P3. In effect NALAP is in consonance with the 2004 policy.

As part of the research on the implementation of NALAP, a questionnaire, prepared for teachers, sought information about them and their pupils. With regard to the teachers, there were questions related to their background training and teaching experience, their first language, the language policy they were expected to implement, 
whether or not they agreed with the policy, availability or otherwise of language teaching and learning materials, etc. The teachers were also asked to indicate class enrolment, pupils' L1, pupils' proficiency level in the local language and in English. Head teachers were interviewed and language classes were observed where possible. Altogether nine public Basic Schools were visited in the Eastern Region and ninetyfour (94) teachers completed the questionnaire. In the Greater Accra Region, six Basic Schools, consisting of two private and four public schools were involved in the investigation and fifty-six (56) teachers participated in the study.

\section{Results of the Survey}

\subsection{Teachers' Knowledge of 2004 Language Policy in Education}

To assess teachers' knowledge and understanding of the policy, the questionnaire requested them to state the medium of instruction for KG 1 through P3.

Eastern Region: Of the 92 teachers who responded to this item, $5(5.4 \%)$ indicated that it was English, 70 (76\%) mentioned the local language, 17 (18.5\%) said both English and the local language were to be used. A similar question was asked concerning P4P6. Eighty-eight (88) (95.6\%) selected English and 5 (5.4\%) chose local language and English. Regarding when English was to be introduced to children, many of them responded that it was to begin in P4. As many as 42 (45.6\%) selected P4; 20 (21.7\%) said it was in KG; 19 (20.6\%) mentioned P1 and 7 (7.6\%), P3.

Greater Accra: The return rate of the questionnaire in the Greater Accra Region was rather low but the pattern was not different from what emerged in the Eastern Region. Answering the question on the language-in-education policy, $43(76.8 \%)$ of the 56 respondents said the local language was the medium of instruction, $6(10.7 \%)$ said it was English, and 7 (12.7\%) said it was both the local language and English. Concerning the medium of instruction for the Upper Primary ( $\mathrm{P} 4-6)$, all the respondents, except one, said it was English. On the introduction of English, 25 (46.3\%) reported that it was in $\mathrm{P} 4,12$ (22.2\%) said it was KG, 10 (18.5) P1, and 4 (7.4\%) chose P3.

\subsection{Local Language Proficiency of Teachers and Pupils}

The implementation of the 2004 policy would be feasible if KG1 - P3 teachers were proficient in and trained to teach in both English and the local language.

Eastern Region: Of the ninety-three teachers who indicated their L1, eighty-one were native speakers of the language of the area; all the others also reported fluency in that 
language. Concentrating on the lower primary level, where the use of the local language is crucial, I found that the twenty-two teachers who taught KG1 - P3 had native competence in the local language. Similarly, of the 1,846 children enrolment in KG 1 through P6, only twenty-five were reported to speak other languages as L1. However, further investigation revealed that these children were born in the area, and were in fact, bilingual first language speakers, that is, they learned the language spoken by their parents and that of the area simultaneously. Also, all the 749 lower primary children (KG 1 - P3) were reported to be fluent speakers of the local language.

Greater Accra: The teachers in the survey belonged to three main linguistic groups; 26 (46.43\%) spoke Akan, 17 (30.4\%) spoke Ewe, 12 (21.4\%) spoke Ga, 1 (1.8\%), Nzema and $1(1.8 \%)$ Buli. Note that the first three languages in this list are also the majority languages in Ghana. Asked whether they spoke any other Ghanaian language, 24 $(42.8 \%)$ indicated Akan, $22(39.2 \%) \mathrm{Ga}$, and 5 (8.9\%) Ewe. On the first language of the children, in each of the schools Akan, Ewe and Ga appeared in the responses though the teachers could not provide the exact number of children who spoke each of these languages as L1. Many of the teachers also simply wrote 'mixed', meaning that the children came from different linguistic backgrounds. Another interesting fact that emerged in the survey was that some teachers from the same school gave different answers to the question that required them to state the language spoken in the locality. Again, Akan, Ga and Ewe were reported.

\subsection{Level of implementation of 2004 policy}

Eastern Region: The statistics obtained in the Eastern Regions would suggest that the 2004 policy, that 'where teachers and learning materials are available and linguistic composition of classes is fairly uniform, the children's first language must be used as the dominant medium of instruction in kindergarten and lower primary' (Government White Paper, pp. $27 \& 28$ ) would be implemented in the nine schools. This happened to be the case. The KG1 - P3 teachers reported that they used both the local language and English in instruction, even though some of them could not state the language policy accurately. All the schools visited reported that KG $1-\mathrm{P} 3$ teachers had been trained in the use of the new programme and were following its guidelines. Most of the teachers claimed that they had adequate textbooks and teaching materials for both English and local language classes. Also, P1-P3 children were being taught to read and write in both languages; this report was confirmed through class observation and examination of children's exercise books. 
Greater Accra: The picture was very different here. Asked whether they taught in a Ghanaian language in their schools, only three of the KG $1-\mathrm{P} 3$ teachers answered in the affirmative. Of this number, it appeared that two perceived English as a Ghanaian language for when they were asked to name the textbook they used in teaching the school subjects, they wrote the title of their English textbooks. The conclusion then is that the 2004 policy was not being implemented effectively in the six schools surveyed in the region. The factors leading to this situation will be discussed presently.

\section{Discussion of Results}

The results indicated above paint a disturbing picture about the implementation of the 2004 policy. First, teachers in both regions seem to have inadequate knowledge and understanding of the 2004 policy they are expected to implement. Regarding the proficiency level of children and teachers in the language of the areas, as already mentioned, Akan is the most widely spoken of the estimated forty-four languages in the country as reported by Kropp-Dakubu et al. 1988. (Simons G. F. \& Fennig 2018 put the number at seventy-three.) Akan is the first language of $40 \%$ of the population and is learned as a second or third language by a large proportion of the other speakers. The finding that all the teachers and children in the schools surveyed in the Eastern Region were fluent in the local language might be due to Akan being a majority language, and also the fact that the schools were located in largely monolingual rural communities. The survey in the Greater Accra Region tells a different story. The teachers in the six schools came from three main language backgrounds: Akan, Ewe, Ga in that order in terms of numbers. However, according to the teachers, even though the dominant language of the locality was not $\mathrm{Ga}$, the District Education office had directed them to use $\mathrm{Ga}$ as the language of instruction alongside English in KG1 - P3 and to be taught as a subject from P4 onwards. Since most of the teachers and the pupils did not speak $\mathrm{Ga}$, (as reported in the preceding section) the teachers simply set aside the directive and taught all the school subjects in English. Explaining why she did not teach in a Ghanaian language, a head teacher indicated that she had petitioned the Ghana Education Service to allow her school to use Akan or Ewe as language of instruction, but her appeal had been turned down. It needs to be clarified that the GES at the time of the research had mandated Ga to be used alongside English in all Basic Schools located in the Greater Accra Region in contravention of the policy which the GES itself was expected to implement. This one-size-fit-all policy for the region seems to have 
been influenced by political considerations rather than educational and pedagogic ones. $^{4}$

Another issue stemming from the above is that NALAP involves only eleven of the languages in the country. These are Asante (Ashanti) Twi, Akuapim (Akwapim) Twi, and Fante (Mfantse), Ewe, Ga, Dangme, Dagbane, Nzema, Dagaare, Gonja, and Kasem. Note that the first three of the list are mutually comprehensible and are classified by linguists as dialects of the same language, Akan, but are treated as separate languages in the school system. This fact then reduces the number of languages employed in NALAP to nine. This implies that many children are not receiving content knowledge and literacy in their first languages.

Related to the preceding point, endorsing seven languages, the GES Acting Deputy Director at the time of the investigation, Mr. Adu, argued that most minority language groups in Ghana were fluent in the dominant languages spoken in their regions, and therefore these bilinguals were expected to be taught in the dominant or second languages. However, some researchers have pointed out that this assertion might not be accurate and that children taught in their second languages might not have enough competence to understand lessons delivered in those languages, and that they might be disadvantaged in their school performance compared to the native speakers. Indeed, some researchers have shown that this is the case. For example, Dovlo (2011) compares the school achievement of speakers of Logba (a minority language in the Volta Region) who are taught in Ewe, the dominant language, with native Ewe speakers. He reports that the Logba children had a lower proficiency in Ewe, and consequently, a lower school achievement than their native Ewe counterparts.

Another implementation issue is the position of ethnic groups whose languages are not currently provided for in the school system. For example, the then Acting Deputy Director General of GES told this writer that NALAP was not being implemented in the whole of the Upper East Region, one of the ten administrative areas of Ghana. He explained that speakers of Gurene, the language of the regional capital, Bolgatanga, were insistent that their language had a bigger population and was spoken in a wider geographical area than Kasem, which had government approval to be used as the language of instruction in KG1 - P3 and subsequently to be taught as a subject in the whole region. They added that the assertion that speakers of Gurene were also fluent in Kasem was inaccurate. They called into question the criteria used by policy

\footnotetext{
${ }^{4}$ For many years, the opinion leaders of the Ga, the original settlers of the Greater Accra Region, have complained that the presence of another major indigenous language in their area is undermining the use of Ga in their territory. The GES probably succumbed to pressure to remain inflexible in the policy in order to avoid the displeasure of the Ga people.
} 
makers in their decision to endorse one language rather than another. Consequently, at the time of the research, NALAP therefore did not have the support of Gurene scholars and opinion leaders, who had also influenced teachers in their area to set aside the policy. It needs to be mentioned that Gurene speakers were not alone in their displeasure about the exclusion of their language from government endorsement.

Such protestations indicate two things; a) the importance of accurate linguistic and sociolinguistic facts that are relevant to language planning and language policy, and b) the need for policy makers to work in close consultation with the affected groups instead of imposing policy on them. Note that several multilingual countries the world over, have encountered similar challenges in language policy implementation. For example, Webb (2002) recalls the situation that occurred

in South Africa when the Apartheid government decided that Afrikaans should be the medium of instruction in secondary schools along with English. Teachers and students rejected this decision, arguing that the teachers and pupils weren't proficient enough in Afrikaans, that textbooks were not available in Afrikaans, and that the people directly affected by the policy decision had never been consulted. The government, of course, rejected the objections of the teachers and pupils, and there was a direct confrontation between protesting pupils and police. (Webb 2002:5)

This well-known Soweto incident, which initially centred on language policy, shows clearly how central language is to many aspects of national life and the need for policies of inclusion rather than exclusion because of the far-reaching consequences that can be engendered when communities feel that their rights and interests are unjustifiably ignored.

In the case of Ghana, the non-adherence to NALAP as described in the preceding paragraphs seems to undermine a major policy of the Ghana Education Service. To graduate from the JHS level to SHS, students were required to pass in some core subjects, including Ghanaian Language. Since local language study is excluded from the school curriculum in the Upper East Region, the GES was compelled to modify the above criterion to exclude Ghanaian Language study from the list. This decision is likely to affect the level of attention that teachers and students might devote to the teaching and study of the local language since it is no longer a JHS graduation requirement.

From the discussion above, one can infer that there is the underlying assumption by those in authority that everyone will learn English and thereby participate in 
governance and decision making at all levels. This manner of thinking does not take into consideration the reality. First, according to the 2000 census, $51 \%$ of the people are literate, speaking and writing in English. Though Simons and Fennig (2018) put the current literacy rate at $71 \%$, it is necessary to add that a large percentage of the so-called English speakers do not have the level of proficiency that would enable them to participate meaningfully in major national discussions in that language. Second, formal education, which is the main avenue for the acquisition of English, is not available to a large percentage of the Ghanaian population. Compulsory education became a policy in Ghana in the early 1960s when Nkrumah's administration launched the Five-Year Development Plan. As part of this plan, every child in Ghana was supposed to receive elementary education. In practice, the policy was never enforced. In the 1990s, the Free, Compulsory, Universal Basic Education (FCUBE) was also launched. More than almost three decades on, basic education is still not accessible and not compulsory and not universal as a sizable percentage of Ghanaian children still remain outside the school system with many of them roaming the streets of the cities.

Currently, teaching in the local languages may not be attractive to many parents, students and teachers because competence in those languages does not seem to matter in educational, social and economic advancement. However, insistence on English only as the language of instruction at the lowest level of education, with the current high rate of pupils' failure in attaining appreciable proficiency levels, consigns many JHS leavers to the bottom of society. The social and economic cost to the nation stemming from lives that are thus jeopardized cannot be quantified in monetary terms. On the other hand, there is no guarantee that English will become the national language and the language of choice any time soon. Even if Ghana was lucky to achieve this feat of getting all its citizens to communicate effectively in English, making the local languages redundant, there are many reasons why the local languages should not be ignored, but these cannot be discussed here. Suffice it to say that the accumulated indigenous knowledge and the cultures embodied in those languages would gradually be lost.

An offshoot of the minimal attention given to the local language in Ghana's education system is that gradually but steadily many Ghanaians acquire and use English as their first language, having very little or no proficiency at all in a local language. Generally, such individuals become part of the elite, the opinion leaders and the people's representatives in governance. If the educational system gives these individuals the opportunity to become true bilinguals who have the flexibility to speak, read and write in a local language as well as in English, they would be able to communicate better with the non-English speaking masses of the population. 


\section{Recommendations}

The preceding survey has revealed that attempts are being made to implement the 2004 language-in-education policy in some monolingual areas of the Eastern Region of Ghana while implementation has stalled in some multilingual territories of the Greater Accra Region due to the multiple languages spoken by the children and their teachers. The directive that in this region, Ga should be used as the language of instruction in all lower primary schools and also be taught as a subject from Primary 4 and beyond does not take into account the nature of the populations of the schools. It appears some flexibility in the choice of language of instruction in this region is necessary. Also, for NALAP to work for most children, if not all, the role of teachers should not be underestimated since they are the major players in what actually happens in the schools. In that regard, teacher proficiency in the indigenous language should be taken into account in the process of teacher posting. Similarly, teachers need to be educated to understand the policy and be provided with clear guidelines for effective implementation. Furthermore, to give true meaning to the NALAP principle of providing content knowledge and initial literacy to children in their own languages, it is essential for the Ministry of Education to draw up a plan through which it would gradually endorse most of the indigenous languages for use in schools. This should be the ultimate aim of NALAP, but until that goal is achieved, decisions regarding which indigenous language to be used in which locality should involve the affected communities in order to gain their full support and cooperation. (See also a report emanating from the School of Languages conference held at the University of Ghana, Legon in 2015.) ${ }^{5}$

\section{Conclusion}

This paper has focused on the frequent changes and inconsistencies associated with language in education policies endorsed by different administrations of Ghana. While some of the policies require that English, a world language and a major linguistic capital in contemporary times, which is also the adopted official language of the country, be used as the medium of instruction at the lowest level of education, others approve the local language medium at that stage, while still others allow the use of both English and the local language for the same purpose. As discussed in this paper, NALAP principles,

\footnotetext{
${ }^{5}$ Report to the Minister on the first School of Languages Conference (SOLCON 1) held at the Institute of Statistical, Social and Economic Research (ISSER) Conference Facility, University of Ghana, from $27^{\text {th }}$ to $29^{\text {th }}$ October, 2015. Theme: 'Multilingualism in the African Context: A Challenge or Resource?'
} 
are in line with the existing policy which endorses the local language medium at the lowest level (KG - P2/3) and encourage the teaching of English as a subject at that stage as well. An investigation into the level of implementation of NALAP in the schools reveals that while it is quite successful in some monolingual communities, there are a number of challenges associated with it in multilingual areas. The paper ends with suggestions for addressing those implementation bottlenecks. 


\section{References}

Ansah, G. N. 2014. "Re-examining the fluctuations in language-in-education policies in post-independence Ghana." Multilingual Education 4:12.

Anyidoho, Akosua. 2004. "English-only medium of instruction?" Legon Journal of Humanities XV: 81-97.

Anyidoho, Akosua and Mary Esther Kropp Dakubu. 2008. "Indigenous Languages, English and an Emerging National Identity." In Language and National Identity in Africa, edited by Andrew Simpson. Oxford: Oxford University Press.

Anyidoho, Akosua and Nana Akua Anyidoho. 2009. "Ideological and political considerations in the choice of school language." In Supplement of Research Review, edited by M.E. Dakubu and A. A. Ampofo, 9: 9-34. Institute of African Studies.

Boadi, Lawrence. 1976. "Mother Tongue Education in Ghana." In Mother Tongue Education: The West African Experience, edited by Ayo Bamgbose, 83-112. London: Hodder and Stoughton.

"Brief Report on the National Literacy Acceleration Programme." Undated and unpublished document obtained from the GES head office in Accra in June 2011.

Budu-Smith, John. "Reminder on the policy of the use of Ghanaian language as the medium of instruction in Primary 1- 3 Schools." (Unpublished letter dated January 29, 2001, obtained from the GES head office in Accra.)

Budu-Smith, John. "The implementation of the New Ghanaian Language Policy." (Unpublished letter dated August 6, 2002, obtained from the GES head office in Accra.)

Dakubu, M. E. Kropp and Florence Dolphyne. Eds. 1988. Languages of Ghana. London: Kegan Paul International.

Dorvlo, Kofi. 2011. "Language use in education in Minority language areas: The case of Logba." In Identity Meets Nationality: Voices in the Humanities, edited by Helen Lauer, Nana Aba Appiah Amfo, Jemina Asabea Anderson, 100-111. Accra: Sub-Saharan Publishers.

Markin-Yankah, Marian. 1999. "Language Policy in Basic Education- An Assessment of its Implementation in the Shama-Ahanta East District." M.Phil. thesis, Department of Linguistics, University of Ghana, Legon.

McWilliam, H.O.A. and M.A. Kwamena-Poh. 1975. The Development of Education in Ghana. London: Longman Group.

Nkansa-Kyeremateng, K. 1996. History, Mission and Achievements: The Presbyterian Church, Ghana. Accra: Sebewie Publishers. 
Nyamekye, Kwabena. "Opening address at National Education Assessment Trainer of Trainers Test Administration and Monitoring Training Workshop." Speech delivered at a Ghana Education workshop held in Ho, June 2011.

Owu-Ewie, C. 2006. "The language policy of education in Ghana: a critical look at the English-only language policy of education." In Selected Proceedings of the 35th Annual Conference on African Linguistics, edited by J. Mugane, 76-85. MA: Cascadilla Proceedings Project.

Report to the Minister on the first School of Languages Conference (SOLCON 1) held at the Institute of Statistical, Social and Economic Research (ISSER) Conference Facility, University of Ghana, from $27^{\text {th }}$ to $29^{\text {th }}$ October, 2015. Theme: 'Multilingualism in the African Context: A Challenge or Resource?'

Simons, G. F. and C.D. Fennig, eds. 2018. Ethnologue: Languages of the World, Twenty-first edition. Dallas, Texas: SIL International. Online version: http://www.ethnologue.com.

Webb, Vic. 2002. Languages in South Africa: the role of language in national transformation, reconstruction and development. Amsterdam/Philadelphia: John Benjamins Publishing Company.

White Paper on the Report of the Education Review Committee chaired by J. Anamoah Mensah, dated 2004. 